\title{
Alpha Fetoprotein L3 to Total Alpha Fetoprotein Ratio Measurement
}

National Cancer Institute

\section{Source}

National Cancer Institute. Alpha Fetoprotein L3 to Total Alpha Fetoprotein Ratio

Measurement. NCI Thesaurus. Code $C 96565$.

The determination of the ratio of alpha fetoprotein L3 compared to total alpha

fetoprotein present in a sample. The measurement may be expressed as a ratio or percentage. 